\title{
Comparison of one-jaw and two-jaw orthognathic surgery in patients with skeletal Class 111 malocclusion using data from 10 multi-centers in Korea: Part 1. Demographic and skeletodental characteristics
}

\author{
Seung-Weon $\mathrm{Lim}^{\mathrm{a}}$ (1) \\ Minsoo Kim $^{\mathrm{b}}$ \\ Mihee $\mathrm{Hong}^{\mathrm{c}}$ \\ Kyung-Hwa Kang ${ }^{\mathrm{d}}$ \\ Minji Kim ${ }^{\mathrm{e}}$ \\ Su-Jung Kim ${ }^{f}$ \\ Yoon-Ji Kim ${ }^{g}$ \\ Young Ho Kim ${ }^{\text {h }}$ \\ Sung-Hoon Lim \\ Sang Jin Sung ${ }^{g}$ \\ Seung-Hak Baek \\ Jin-Hyoung $\mathrm{Cho}^{\mathrm{k}}$ (10)
}

${ }^{a}$ Division of Orthodontics, Department of Dentistry, Hanyang University Hospital, Seoul, Korea

${ }^{b}$ Department of Statistics, College of Natural Sciences, Chonnam National University, Gwangju, Korea

'Department of Orthodontics, School of Dentistry, Kyungpook National University, Daegu, Korea

${ }^{d}$ Department of Orthodontics, School of Dentistry, Wonkwang University, lksan, Korea 'Department of Orthodontics, College of Medicine, Ewha Womans University, Seoul, Korea

'Department of Orthodontics, Kyung Hee University School of Dentistry, Seoul, Korea

${ }^{g}$ Department of Orthodontics, Asan Medical Center, University of Ulsan College of Medicine, Seoul, Korea hepartment of Orthodontics, Institute of Oral Health Science, Ajou University School of Medicine, Suwon, Korea 'Department of Orthodontics, College of Dentistry, Chosun University, Gwangju, Korea Department of Orthodontics, School of Dentistry, Dental Research Institute, Seoul National University, Seoul, Korea ${ }^{k}$ Department of Orthodontics, Chonnam National University School of Dentisto

Gwangju, Korea

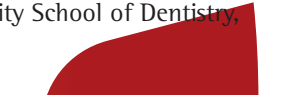

\begin{abstract}
Objective: To investigate demographic and skeletodental characteristics of one-jaw (1J-OGS) and two-jaw orthognathic surgery (2J-OGS) in patients with skeletal Class 111 malocclusion. Methods: 750 skeletal Class 111 patients who underwent OGS at 10 university hospitals in Korea between 2015 and 2019 were investigated; after dividing them into the 1J-OGS $(n=186)$ and 2J-OGS groups $(n=564)$, demographic and skeletodental characteristics were statistically analyzed. Results: 2J-0GS was more frequently performed than 1J-OGS (75.2 vs. $24.8 \%$ ), despite regional differences (capital area vs. provinces, 86.6 vs. $30.7 \%, p<0.001$ ). Males outnumbered females, and their mean operation age was older in both groups. Regarding dental patterns, the most frequent maxillary arch length discrepancy (ALD) was crowding in the 1J-0GS group (52.7\%, $p<0.001)$ and spacing in the $2 \mathrm{~J}-0 \mathrm{GS}$ group $(40.4 \%, p<0.001)$. However, the distribution of skeletal pattern was not significantly different between the two groups (all $p>0.05$ ). The most prevalent skeletal patterns in both groups were hyper-divergent pattern (50.0 and 54.4\%, respectively) and left-side chin point deviation (both 49.5\%). Maxillary spacing (odds ratio [OR], 3.645; $p<0.001$ ) increased the probability of 2J-OGS, while maxillary crowding $(\mathrm{OR}, 0.672 ; p<0.05)$ and normo-divergent pattern $(\mathrm{OR}, 0.615$; $p<0.05)$ decreased the probability of 2J-0GS. Conclusions: In both groups, males outnumbered females, and their mean operation age was older. The most frequent ALD was crowding in the 1J-OGS group, and spacing in the 2J-OGS group, while skeletal characteristics were not significantly different between the two groups.
\end{abstract}

[Korean J Orthod 2022;52(1):66-74]

Key words: Class 111 orthognathic surgery, Class 111 diagnosis, Class 111 treatment

Received April 5, 2021; Revised July 5, 2021; Accepted August 9, 2021.

Corresponding author: Jin-Hyoung Cho.

Professor and Chair, Department of Orthodontics, Chonnam National University School of Dentistry, 33 Yongbong-ro, Buk-gu, Gwangju 61186, Korea.

Tel+82-62-530-5818 e-mail jhcho@chonnam.ac.kr

How to cite this article: Lim SW, Kim M, Hong M, Kang KH, Kim M, Kim SJ, Kim YJ, Kim YH, Lim SH, Sung SJ, Baek SH, Cho JH. Comparison of one-jaw and two-jaw orthognathic surgery in patients with skeletal Class 111 malocclusion using data from 10 multi-centers in Korea: Part 1. Demographic and skeletodental characteristics. Korean J Orthod 2022;52:66-74.

(C) 2022 The Korean Association of Orthodontists.

This is an Open Access article distributed under the terms of the Creative Commons Attribution Non-Commercial License (http://creativecommons.org/licenses/by-nc/4.0) which permits unrestricted non-commercial use, distribution, and reproduction in any medium, provided the original work is properly cited. 


\section{INTRODUCTION}

With the advancement of orthognathic surgery techniques, patients with severe skeletal discrepancies such as prognathism, retrognathism, and asymmetry can have the opportunity to undergo skeletal correction. ${ }^{1,2}$ The most prevalent skeletal discrepancy of the patients undergoing orthognathic surgery has been reported as skeletal Class 111 malocclusions. ${ }^{3-9}$ This is also demonstrated in the Korean population, which has a high prevalence of Class 111 malocclusions and a negative social perception of the prognathic appearance. ${ }^{9-18}$ Therefore, Korean has become one of the countries performing orthognathic surgery extensively in patients with skeletal Class 111 malocclusions.

Regarding the clinical characteristics of the skeletal Class 111 malocclusion, complex vertical and transverse skeletal problems are usually accompanied by sagittal problems. The excessive downward growth of the maxilla resulting in a flat occlusal plane (OP) is commonly exhibited with the mandibular overgrowth. ${ }^{19}$ In addition, transverse problems, such as chin point deviation (CPD) and OP cant, commonly occur in patients with skeletal Class 111 malocclusions. ${ }^{19,20}$ Therefore, the severity of the malocclusion and skeletal discrepancy, unattractiveness of facial appearance, the effectiveness of the pre- and post-surgical orthodontic treatment, surgical risks, and financial concerns should be comprehensively evaluated before deciding orthognathic surgical modality. ${ }^{21-23}$

There are two common types of orthognathic surgery to correct skeletal Class 111 malocclusions: one-jaw orthognathic surgery (1J-OGS; mandible only approach), and two-jaw orthognathic surgery (2J-OGS; bimaxillary approach). ${ }^{21} 1 \mathrm{~J}-0 \mathrm{GS}$ usually involves the posterior setback movement of the mandible without interfering with the maxilla. This modality is less invasive and requires a lower cost than the 2J-OGS. However, the sagittally flat or transversely canted maxillary OP is hard to be corrected with 1J-OGS alone; hence it should be corrected with pre- or postsurgical orthodontic treatment. ${ }^{24}$ In addition, the proclined maxillary incisors, which generally occur due to dental compensation, should be normalized with orthodontic treatment. ${ }^{25,26}$ For this reason, the maxillary premolars are frequently extracted while establishing Class 11 molar relation with an increased mandibular setback. ${ }^{26,27}$ On the other hand, 2J-OGS enables correction of the torque of the maxillary incisor as well as sagittally flat or transversely canted OP by a single operation. ${ }^{28,29}$ However, this is not only more invasive and technically difficult, but also incurs a higher cost than 1J-OGS. ${ }^{21-23}$

Even though there have been numerous investigations regarding orthognathic surgery for patients with skeletal Class 111 malocclusions, their characteristics in relation to the surgical modalities have not been well documented. ${ }^{3}$
Therefore, it would be necessary to investigate the demographic and skeletodental characteristics concerning these surgical modalities to provide qualitative and quantitative information beneficial to both clinicians and patients. In this study, the recent demographic data of orthognathic surgery patients with skeletal Class 111 malocclusions were obtained from 10 multi-centers nationwide. In addition, the patient's clinical characteristics involving skeletodental patterns were investigated and compared between and within the 1J-OGS and 2J-OGS groups. This retrospective study aimed to investigate the demographic and skeletodental characteristics of 1J-OGS and 2J-OGS in patients with skeletal Class 111 malocclusions using data from 10 multi-centers in Korea.

\section{MATERIALS AND METHODS}

\section{Subjects}

The initial samples consisted of 1,073 Korean adults who underwent orthognathic surgery at 10 University Hospitals in Korea between 2015 and 2019. They were randomly selected from the Department of Orthodontics of 10 multi-centers as follows: Seoul National University Dental Hospital (SNUDH, $\mathrm{n}=513$ ), Kyung Hee University Dental Hospital (KHUDH, $\mathrm{n}=213$ ), Kyungpook National University Dental Hospital (KNUDH, $\mathrm{n}=55$ ), Asan Medical Center (AMC, $n=52$ ), Ajou University Dental Hospital (AUDH, $n=42)$, Korea University Anam Hospital (KUAH, $n=40$ ), Chonnam National University Dental Hospital (CNUDH, $n=40$ ), Wonkwang University Dental Hospital (WUDH, $n=40$ ), Ewha Womans University Medical Center (EUMC, $n=43$ ), and Chosun University Dental Hospital (CSUDH, $\mathrm{n}=35$ ).

Young Korean adults diagnosed with skeletal Class 111 malocclusions and whose age was above 18 years with the completion of facial growth were included. Patients whose charts were not available were excluded.

Finally, we collected the data of 750 Korean adult patients as the final samples from Department of Orthodontics in SNUDH $(n=302), \mathrm{KHUDH}(\mathrm{n}=149), \mathrm{KNUDH}$ $(n=44)$, AMC $(n=46)$, AUDH $(n=31)$, KUAH $(n=35)$, CNUDH $(n=38)$, WUDH $(n=36)$, EUMC $(n=34)$, and CSUDH $(\mathrm{n}=35)$. They were divided into the 1J-OGS ( $\mathrm{n}$ = 186; mandible only; 104 males and 82 females) and $2 J-0 G S$ groups $(\mathrm{n}=564 ; 306$ males and 258 females; Table 1). In addition, AMC, AUDH, EUMC, KHUDH, $\mathrm{KUAH}$, and SNUDH were categorized as the capital region hospitals, while CNUDH, CSUDH, KNUDH, and WUDH were categorized as the provincial region hospitals according to their geographical locations in Korea (Figure 1).

This study was reviewed and approved by the Institutional Review Board (IRB) Committee of 10 multicenters; including SNUDH (ERl18002), KHUDH (D19- 
Table 1. Composition of the subjects

\begin{tabular}{lccc}
\hline & Final & \multicolumn{2}{c}{ Surgical modality } \\
\cline { 3 - 4 } \multicolumn{1}{c}{ University Hospitals } & samples & $\begin{array}{c}\text { One-jaw } \\
\text { orthognathic surgery } \\
\text { (1J-OGS) group }\end{array}$ & $\begin{array}{c}\text { Two-jaw } \\
\text { orthognathic surgery } \\
\text { (2J-OGS) group }\end{array}$ \\
\hline Asan Medical Center (AMC) & $46(6.1)$ & $6(13.0)$ & $40(87.0)$ \\
Ajou University Dental Hospital (AUDH) & $31(4.1)$ & $10(32.3)$ & $21(67.7)$ \\
Chonnam National University Dental Hospital (CNUDH) & $38(5.1)$ & $20(52.6)$ & $18(47.4)$ \\
Chosun University Dental Hospital (CSUDH) & $35(4.7)$ & $33(94.3)$ & $2(5.7)$ \\
Ewha University Medical Center (EUMC) & $34(4.5)$ & $9(26.5)$ & $25(73.5)$ \\
Korea University Anam Hospital (KUAH) & $35(4.7)$ & $11(31.4)$ & $24(68.6)$ \\
Kyung Hee University Dental Hospital (KHUDH) & $149(19.9)$ & $28(18.8)$ & $121(81.2)$ \\
Kyungpook National University Dental Hospital (KNUDH) & $44(5.9)$ & $35(79.5)$ & $9(20.5)$ \\
Seoul National University Dental Hospital (SNUDH) & $302(40.3)$ & $16(5.3)$ & $286(94.7)$ \\
Wonkwang University Dental Hospital (WUDH) & $36(4.8)$ & $18(50.0)$ & $18(50.0)$ \\
Total & 750 & $186(24.8)$ & $564(75.2)$ \\
\hline
\end{tabular}

Values are presented as number (\%).
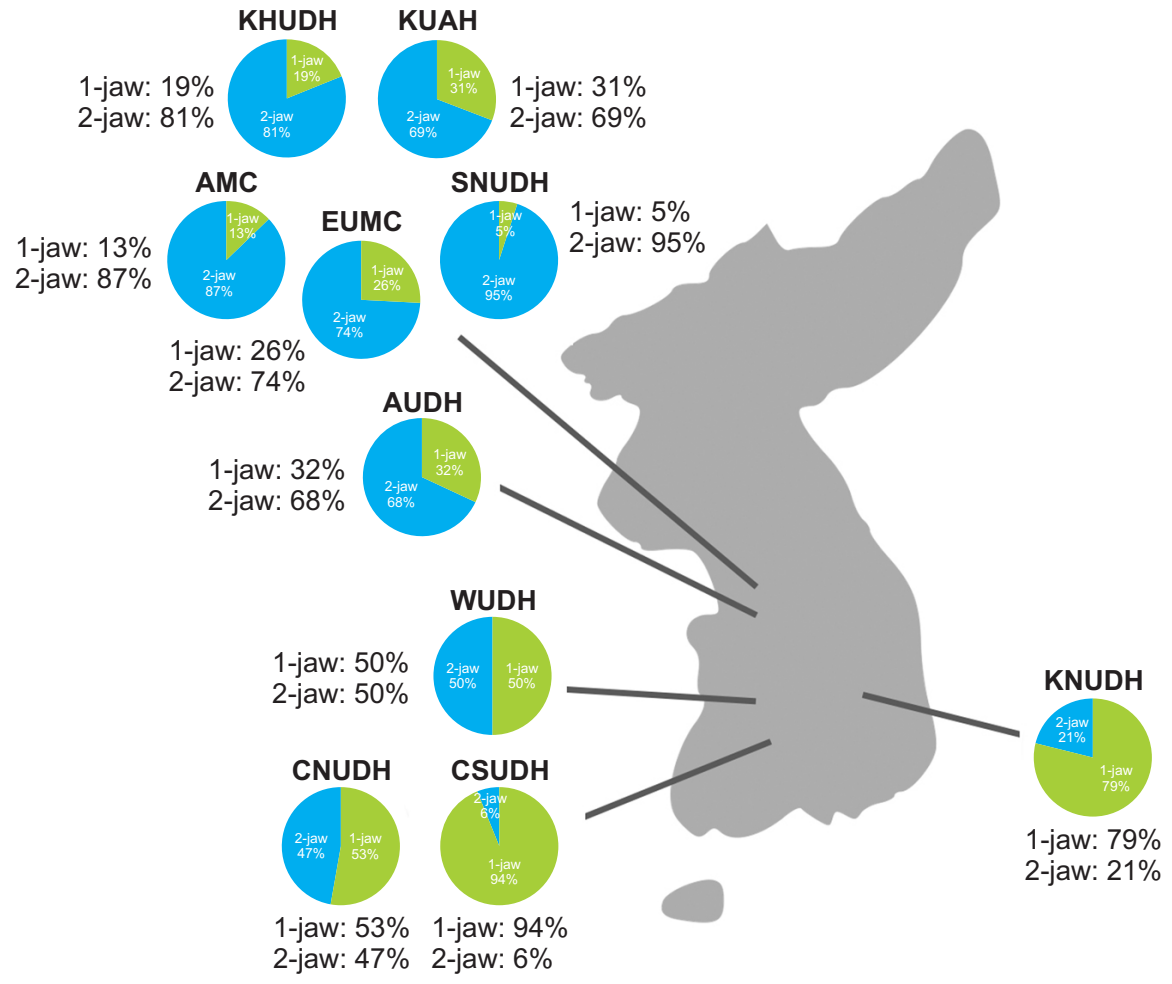

Figure 1. Frequency of $1 \mathrm{~J}-\mathrm{OGS}$ and $2 \mathrm{~J}-\mathrm{OGS}$ in 10 University Hospitals. AMC, AUDH, EUMC, KHUDH, KUAH, and SNUDH were categorized as the capital region hospitals, while $\mathrm{CNUDH}$, CSUDH, KNUDH, and WUDH were categorized as the provincial region hospitals.

1J-OGS, one-jaw orthognathic surgery; 2J-OGS, two-jaw orthognathic surgery; AMC, Asan Medical Center; AUDH, Ajou University Dental Hospital; EUMC, Ewha University Medical Center; KHUDH, Kyung Hee University Dental Hospital; KUAH, Korea University Anam Hospital; SNUDH, Seoul National University Dental Hospital; CNUDH, Chonnam National University Dental Hospital; CSUDH, Chosun University Dental Hospital; KNUDH, Kyungpook National University Dental Hospital; WUDH, Wonkwang University Dental Hospital. 
007-003), KNUDH (KNUDH-2019-03-02-00), AMC (2019-0927), AUDH (AJIRB-MED-MDB-19-039), KUAH (2019AN0166), CNUDH (CNUDH-EXP-2021-001), WUDH (WKDIRB202010-06), EUMC (EUMC 2019-04-017-003), and CSUDH (CUDHIRB 1901 005). The requirement for patient consent was waived by the IRB Committee of each center.

\section{Variables}

Demographic characteristics (sex and operation age) and skeletodental characteristics were investigated. The dental patterns included overbite (normal overbite, deep bite, open bite) and maxillary arch length discrepancy (ALD) (crowding, spacing, no ALD). The skeletal patterns included vertical discrepancy (hyper-divergent, normo- divergent, hypo-divergent) and transverse discrepancy (presence of CPD or OP cant) (Table 2).

\section{Statistical analysis}

An independent $t$-test and a chi-square goodness of fit test were performed to compare the demographic and skeletodental characteristics between 1J-OGS and 2J-OGS groups and within each group. Binary logistic regression analysis was also performed to investigate the effects of the demographic and skeletodental characteristics on the decision for surgical modality (1J-OGS or 2J-0GS). The impact of each factor on the outcome variable was expressed as an odds ratio (OR) with a 95\% confidence interval.

All statistical analysis was conducted using Statistical

Table 2. Criteria for the categorization of the dental and skeletal patterns

\begin{tabular}{llllll}
\hline \multicolumn{3}{c}{ Dental patterns } & & & Skeletal patterns \\
\hline Overbite & $1-3 \mathrm{~mm}$ & Normal & Vertical discrepancy & SN-GoMe, $>39.0^{\circ}$ & Hyper-divergent \\
& $3 \mathrm{~mm}<$ & Deepbite & & SN-GoMe, 29-39 & Normo-divergent \\
& $<1 \mathrm{~mm}$ & Openbite & & SN-GoMe, $<29^{\circ}$ & Hypo-divergent \\
Maxillary ALD & $1 \mathrm{~mm}<$ & Crowding & Transverse discrepancy & $\mathrm{CPD}>2^{\circ}$ & Presence of CPD \\
& $<0 \mathrm{~mm}$ & Spacing & & OP cant $>2 \mathrm{~mm}$ & Presence of OP cant \\
& $0-1 \mathrm{~mm}$ & No ALD & & & \\
\hline
\end{tabular}

ALD, arch length discrepancy; SN, sella-nasion; Go, gonion; Me, menton; CPD, chin point deviation; OP, occlusal plane.

Table 3. Frequency of $1 \mathrm{~J}-0 \mathrm{GS}$ and $2 \mathrm{~J}-\mathrm{OGS}$ in the capital and provincial regions

\begin{tabular}{|c|c|c|c|c|c|c|c|}
\hline \multirow{3}{*}{ Region } & \multicolumn{3}{|c|}{ 1J-OGS group $(n=186)$} & \multicolumn{3}{|c|}{ 2J-OGS group $(n=564)$} & \multirow{3}{*}{$\begin{array}{c}\begin{array}{c}\text { Between the } \\
\text { two groups }\end{array} \\
p \text {-value }\end{array}$} \\
\hline & \multirow{2}{*}{$\mathbf{n}$} & \multirow{2}{*}{$\%$} & Within group & \multirow{2}{*}{$\mathbf{n}$} & \multirow{2}{*}{$\%$} & Within group & \\
\hline & & & $p$-value & & & $p$-value & \\
\hline Total $(\mathrm{n}=750)$ & 186 & 24.8 & \multirow[t]{3}{*}{-} & 564 & 75.2 & \multirow{3}{*}{$<0.001^{* * *}$} & $<0.001^{* * *}$ \\
\hline Capital $(\mathrm{n}=597)$ & 80 & 13.4 & & 517 & 86.6 & & \multirow{2}{*}{$<0.001^{* * *}$} \\
\hline Province $(\mathrm{n}=153)$ & 106 & 69.3 & & 47 & 30.7 & & \\
\hline
\end{tabular}

A chi-square goodness of fit test was performed.

1J-OGS, one-jaw orthognathic surgery; 2J-OGS, two-jaw orthognathic surgery.

${ }^{* * *} p<0.001$.

Table 4. Comparison of sex distribution within each group and between 1J-0GS and 2J-0GS groups

\begin{tabular}{|c|c|c|c|c|c|c|c|}
\hline \multirow{3}{*}{ Sex } & \multicolumn{3}{|c|}{ 1J-OGS group $(n=186)$} & \multicolumn{3}{|c|}{ 2J-OGS group $(n=564)$} & $\begin{array}{l}\text { Between the } \\
\text { two groups }\end{array}$ \\
\hline & \multirow{2}{*}{$\mathbf{n}$} & \multirow{2}{*}{$\%$} & Within group & \multirow{2}{*}{$\mathbf{n}$} & \multirow{2}{*}{$\%$} & Within group & \multirow{2}{*}{$p$-value } \\
\hline & & & $p$-value & & & $p$-value & \\
\hline Male $(n=410)$ & 104 & 55.9 & \multirow{2}{*}{0.107} & 306 & 54.3 & \multirow{2}{*}{$0.043^{*}$} & \multirow{2}{*}{0.694} \\
\hline Female $(n=340)$ & 82 & 44.1 & & 258 & 45.7 & & \\
\hline
\end{tabular}

A chi-square goodness of fit test was performed.

1J-OGS, one-jaw orthognathic surgery; 2J-OGS, two-jaw orthognathic surgery.

${ }^{*} p<0.05$. 
Analysis System (version 12.0; SAS Institute, Cary, NC, USA), and a $p$-value less than 0.05 was considered statistically significant.

\section{RESULTS}

\section{Frequency of $1 \mathrm{~J}-0 \mathrm{GS}$ and $2 \mathrm{~J}-0 \mathrm{GS}$}

Although 2J-OGS was more frequently performed than 1J-OGS in total (75.2 vs. $24.8 \%, p<0.001$, Table 3 ), there was a regional difference; 2J-OGS was more frequently performed in the capital regions, while $1 \mathrm{~J}-$ OGS was in the provincial regions (1J-OGS vs. 2J-OGS; capital regions, 13.4 vs. $86.6 \%$; provincial regions, 69.3 vs. $30.7 \%$, all $p<0.001$, Table 3 , Figure 1).

\section{Comparison of the sex distribution between the two groups and within each group}

There was no significant difference in the sex distribution between the two groups (males and females; 1JOGS group, 55.9 and $44.1 \%$ vs. $2 \mathrm{~J}-\mathrm{OGS}$ group, 54.3 and
45.7\%; $p>0.05$; Table 4). Within each group, males outnumbered females, which was statistically significant only in the 2J-OGS group (males vs. females; 54.3 vs. 45.7\%; $p<0.05$; Table 4).

Comparison of the mean operation age between the two groups and within each group

There was no significant difference in the mean operation age between the two groups (males and females; 1J-OGS group, 24.2 and 22.9 years vs. 2J-OGS group, 23.3 and 22.5 years; $p>0.05$; Table 5 ). Within each group, the mean operation age of males was older than that of females, which was statistically significant only in the 2J-OGS group (male vs. females; 23.3 vs. 22.5 years, $p<0.05$ ).

Comparison of the dental patterns between the groups and within each group

There was no significant difference in the distribution of overbite types between the two groups ( $p>0.05$,

Table 5. Comparison of the mean operation age within each group and between 1J-OGS and 2J-OGS groups

\begin{tabular}{|c|c|c|c|c|c|c|c|}
\hline \multirow{3}{*}{ Operation age } & \multicolumn{3}{|c|}{ 1J-OGS group $(n=186)$} & \multicolumn{3}{|c|}{ 2J-OGS group $(n=564)$} & \multirow{3}{*}{$\begin{array}{c}\begin{array}{c}\text { Between the } \\
\text { two groups }\end{array} \\
p \text {-value }\end{array}$} \\
\hline & \multirow{2}{*}{ Mean } & \multirow{2}{*}{ SD } & Within group & \multirow{2}{*}{ Mean } & \multirow{2}{*}{ SD } & Within group & \\
\hline & & & $p$-value & & & $p$-value & \\
\hline Total $(\mathrm{n}=750)$ & 23.6 & 5.9 & - & 22.9 & 4.6 & - & 0.075 \\
\hline Male $(\mathrm{n}=410)$ & 24.2 & 5.3 & 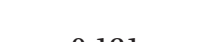 & 23.3 & 4.1 & 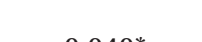 & 0.052 \\
\hline Female $(\mathrm{n}=340)$ & 22.9 & 6.6 & 0.121 & 22.5 & 5.1 & 0.070 & 0.546 \\
\hline
\end{tabular}

An independent $t$-test was performed.

1J-OGS, one-jaw orthognathic surgery; 2J-OGS, two-jaw orthognathic surgery; SD, standard deviation. ${ }^{*} p<0.05$.

Table 6. Comparison of the dental patterns within each group and between 1J-OGS and 2J-OGS groups

\begin{tabular}{|c|c|c|c|c|c|c|c|}
\hline \multirow{3}{*}{ Dental pattern } & \multicolumn{3}{|c|}{$\begin{array}{l}\text { 1J-OGS group } \\
(\mathrm{n}=186)\end{array}$} & \multicolumn{3}{|c|}{$\begin{array}{c}\text { 2J-OGS group } \\
(\mathrm{n}=\mathbf{5 6 4})\end{array}$} & \multirow{3}{*}{$\begin{array}{c}\begin{array}{c}\text { Between the } \\
\text { two groups }\end{array} \\
p \text {-value }\end{array}$} \\
\hline & \multirow{2}{*}{$\mathbf{n}$} & \multirow{2}{*}{$\%$} & \multirow{2}{*}{$\begin{array}{c}\text { Within group } \\
p \text {-value }\end{array}$} & \multirow{2}{*}{$\mathbf{n}$} & \multirow{2}{*}{$\%$} & \multirow{2}{*}{$\begin{array}{c}\text { Within group } \\
p \text {-value }\end{array}$} & \\
\hline & & & & & & & \\
\hline \multicolumn{8}{|l|}{ Overbite } \\
\hline Normal overbite & 99 & 53.2 & \multirow{3}{*}{$\begin{array}{c}<0.001^{* * *} \\
\text { Deep }< \\
\text { (open, normal) }\end{array}$} & 293 & 52.0 & \multirow{3}{*}{ 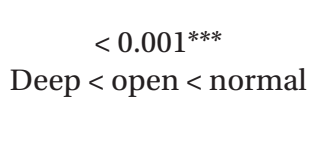 } & \multirow{3}{*}{0.775} \\
\hline Open bite & 76 & 40.9 & & 229 & 40.6 & & \\
\hline Deep bite & 11 & 5.9 & & 42 & 7.4 & & \\
\hline \multicolumn{3}{|c|}{ Arch length discrepancy of maxilla } & \multirow{4}{*}{$\begin{array}{c}<0.001^{* * *} \\
\text { Spacing } \\
<\text { no discrepancy } \\
<\text { crowding }\end{array}$} & & & \multirow{4}{*}{$\begin{array}{c}<0.001^{* * *} \\
\text { (No discrepancy, } \\
\text { crowding) }<\text { spacing }\end{array}$} & \multirow{4}{*}{$<0.001^{* * *}$} \\
\hline No discrepancy & 61 & 32.8 & & 152 & 27.0 & & \\
\hline Crowding & 98 & 52.7 & & 184 & 32.6 & & \\
\hline Spacing & 27 & 14.5 & & 228 & 40.4 & & \\
\hline
\end{tabular}

A chi-square goodness of fit test was performed.

1J-OGS, one-jaw orthognathic surgery; 2J-OGS, two-jaw orthognathic surgery.

*** $p<0.001$. 
Table 6). Within each group, the normal overbite was the most frequent, followed by open bite and deep bite (1J-OGS group, deep bite [5.9\%] < open bite [40.9\%], normal overbite [53.2\%], $p<0.001$; 2J-OGS group, deep bite $[7.4 \%]<$ open bite $[40.6 \%]<$ normal overbite [52.0\%], $p<0.001$, Table 6).

The distribution of maxillary ALD types was significantly different between the two groups $(p<0.001$, Table 6). Crowding was the most frequently observed ALD type in the $1 \mathrm{~J}-\mathrm{OGS}$ group (spacing [14.5\%] < no ALD [32.8\%] < crowding [52.7\%], $p<0.001$, Table 6), while spacing was the most frequently observed in the 2J-0GS group (No ALD [27.0\%], crowding [32.6\%] < spacing [40.4\%], $p<0.001$, Table 6).

\section{Comparison of the skeletal patterns between the two groups and within each group}

There was no significant difference in the distribution of skeletal vertical patterns between the two groups ( $p>0.05$, Table 7$)$. Within each group, the hyperdivergent type was the most prevalent, followed by the normo- and hypo-divergent types (1J-OGS group, hypodivergent type [9.1\%] < normo-divergent type [40.9\%], hyper-divergent type [50.0\%], $p<0.001 ; 2 \mathrm{~J}-0 \mathrm{GS}$ group, hypo-divergent type [9.9\%] < normo-divergent type [35.7\%] < hyper-divergent type [54.4\%], $p<0.001$; Table 7).
In terms of the skeletal transverse patterns, there were no significant differences in the distribution of CPD types between the two groups ( $p>0.05$, Table 7). Within each group, the left-side CPD was the most prevalent, followed by right-side CPD, and no CPD (1J-OGS group, no CPD [19.9\%] < right-side CPD [30.6\%] < left-side CPD [49.5\%], $p<0.001 ; 2$ J-0GS group, no CPD [17.2\%] $<$ right-side CPD [33.3\%] < left-side CPD [49.5\%], $p<$ 0.001; Table 7).

There was no significant difference in the frequency of OP cant between the two groups and within each group $(p>0.05$, Table 7), although OP cant was revealed in more than half of the patients in the 2J-OGS group and less than half of the patients in the 1J-OGS group (1JOGS group, 49.5\%; 2J-OGS group, 52.3\%; all $p>0.05$; Table 7).

Demographic and skeletodental characteristics as indicators for decision of orthognathic surgery modality

Four predictive variables including operation age, crowding, spacing, and normo-divergent pattern were selected after stepwise selection. Therefore, these variables were used in a binary logistic regression analysis. The result showed that spacing and crowding in the maxillary arch and normo-divergent skeletal pattern had a significant association with the decided surgical modality; the probability of $2 \mathrm{~J}-\mathrm{OGS}$ increased when the pa-

Table 7. Comparison of the skeletal vertical and transverse patterns within each group and between $1 \mathrm{~J}-0 \mathrm{GS}$ and $2 \mathrm{~J}-0 \mathrm{GS}$ groups

\begin{tabular}{|c|c|c|c|c|c|c|c|}
\hline \multirow{3}{*}{ Skeletal pattern } & \multicolumn{3}{|c|}{ 1J-OGS group $(n=186)$} & \multicolumn{3}{|c|}{ 2J-OGS group $(n=564)$} & \multirow{3}{*}{$\begin{array}{c}\text { Between the } \\
\text { two groups } \\
\text { p-value }\end{array}$} \\
\hline & \multirow{2}{*}{$\mathbf{n}$} & \multirow{2}{*}{$\%$} & \multirow{2}{*}{$\begin{array}{c}\text { Within group } \\
p \text {-value }\end{array}$} & \multirow{2}{*}{$\mathbf{n}$} & \multirow{2}{*}{$\%$} & \multirow{2}{*}{$\begin{array}{c}\text { Within group } \\
p \text {-value }\end{array}$} & \\
\hline & & & & & & & \\
\hline \multicolumn{8}{|l|}{ Vertical } \\
\hline Hyper-divergent $(\mathrm{n}=400)$ & 93 & 50.0 & \multirow{3}{*}{$\begin{array}{c}<0.001^{* * *} \\
\text { Hypo } \\
<\text { (normo, hyper) }\end{array}$} & 307 & 54.4 & \multirow{3}{*}{$\begin{array}{c}<0.001^{* * *} \\
\text { Hypo }<\text { normo } \\
<\text { hyper }\end{array}$} & \multirow{3}{*}{0.441} \\
\hline Normo-divergent $(\mathrm{n}=277)$ & 76 & 40.9 & & 201 & 35.7 & & \\
\hline Hypo-divergent $(\mathrm{n}=73$ ) & 17 & 9.1 & & 56 & 9.9 & & \\
\hline \multicolumn{8}{|l|}{ Transverse } \\
\hline \multicolumn{8}{|l|}{ CPD } \\
\hline No CPD $(n=134)$ & 37 & 19.9 & \multirow{4}{*}{$\begin{array}{c}<0.001^{* * *} \\
\text { No }<\text { right }<\text { left }\end{array}$} & 97 & 17.2 & \multirow{4}{*}{$\begin{array}{c}<0.001^{* * *} \\
\text { No }<\text { right }<\text { left }\end{array}$} & \multirow{4}{*}{0.645} \\
\hline Presence of CPD $(n=616)$ & 149 & 80.1 & & 467 & 82.8 & & \\
\hline Right-side $(\mathrm{n}=245)$ & 57 & 30.6 & & 188 & 33.3 & & \\
\hline Left-side $(\mathrm{n}=371)$ & 92 & 49.5 & & 279 & 49.5 & & \\
\hline \multicolumn{8}{|l|}{ OP cant } \\
\hline Absence of OP cant $(n=363)$ & 94 & 50.5 & \multirow[t]{2}{*}{0.883} & 269 & 47.7 & 0.274 & \multirow[t]{2}{*}{0.501} \\
\hline Presence of OP cant $(n=387)$ & 92 & 49.5 & & 295 & 52.3 & & \\
\hline
\end{tabular}

A chi-square goodness of fit test was performed.

1J-OGS, one-jaw orthognathic surgery; 2J-OGS, two-jaw orthognathic surgery; CPD, chin point deviation; OP, occlusal plane. *** $p<0.001$. 
Table 8. Demographic and skeletodental characteristics which demonstrated an association with the probability of 2J-OGS

\begin{tabular}{clccc}
\hline $\begin{array}{c}\text { Demographic and } \\
\text { skeletodental characteristics }\end{array}$ & \multicolumn{1}{c}{ 2J-OGS } & OR & 95\% CI & p-value \\
\hline Demographic & Operation age & 0.973 & $(0.941,1.005)$ & 0.10 \\
Dental patterns & Spacing in the maxilla & 3.645 & $(2.236,5.943)$ & $<0.001^{* * *}$ \\
& Crowding in the maxilla & 0.672 & $(0.462,0.980)$ & $0.04^{*}$ \\
Skeletal patterns & Normo-divergent pattern & 0.615 & $(0.429,0.883)$ & $0.01^{*}$ \\
\hline
\end{tabular}

A binary logistic regression analysis was performed.

2J-OGS, two-jaw orthognathic surgery; OR, odds ratio; CI, confidence interval.

${ }^{*} p<0.05,{ }^{* * *} p<0.001$.

tient had spacing in the maxillary arch $(\mathrm{OR}, 3.645 ; p<$ $0.001)$ and decreased when the patient had crowding in the maxillary arch $(\mathrm{OR}, 0.672 ; p<0.05)$ and a normodivergent pattern (OR, 0.615; $p<0.05)$ (Table 8$)$.

\section{DISCUSSION}

Orthognathic surgery was indicated to correct basal bone discrepancies since all the subjects in this study had severe skeletal Class 111 malocclusions that could not be treated with orthodontic treatment alone. ' 2J-OGS was performed for more than three-quarters of the study population (75.2\%, Table 3). Although the dominance of 2J-OGS was coincident with the results of previous studies, the percentage of 2J-OGS in our study was somewhat higher than those reported in studies of other countries. ${ }^{5-8}$ This could be attributed to the differences in ethnic features, since severe skeletal Class 111 malocclusions are more prevalent in the Asian population than in African Americans, Native Americans, and Hispanics populations. ${ }^{16-18}$

When compared with the previous studies on Korean patients, both similarities and differences could be noted in the results of this study. The reasons are as follows: (1) differences in the investigated time; a similar result of 2J-OGS dominance was demonstrated in a study that used comparatively recent data between 2015 and $2019,{ }^{12}$ while 1 J-OGS dominance was observed in the studies that used old data from the late 1990s and early 2000s. ${ }^{13,14}$ (2) the influence of the hospital's region; the data of capital region hospitals demonstrated 2J-OGS dominance $(86.6 \%, p<0.001$, Table 3), while that of provincial region hospitals demonstrated $1 \mathrm{~J}-\mathrm{OGS}$ dominance (69.3\%, $p<0.001$, Table 3$)$. Accordingly, previous Korean studies reported controversial results regarding the dominance of 1J-OGS and 2J-OGS between the provincial (Cheonju and Daegu) and the capital regions (Seoul). ${ }^{9,12-14}$ The regional differences seem to originate from the culture of the metropolitan areas, which more highly value facial appearance and contains more pa- tients with better economic situations.

There were no significant differences in demographic characteristics (sex and mean operation age) between the 1J-OGS and 2J-OGS groups (all $p>0.05$, Tables 4 and 5). Within each group, the males outnumbered females, and their mean operation age was older (Tables 4 and 5). The result of male dominance was different from those of several previous studies, ${ }^{3-11}$ and similar to a recent Korean study. ${ }^{12}$ This male dominance might be due to the increased demand by males for the orthognathic surgery, who were previously unconcerned with their facial appearance. In addition, the older mean operation age of males than females could be because of the obligatory military service in Korea and the late completion of facial growth.

This study revealed statistically significant differences in sex distribution and mean operation age within the 2J-OGS group only (male and female, 54.3 and $45.7 \%$, $p<0.05$, Table 4; 23.3 and 22.5 years, $p<0.05$, Table $5)$, although these differences might not be clinically significant ( $8.6 \%$ and 0.8 years). These significances might result from the difference in sample size between the 1J-OGS $(n=186)$ and the 2J-0GS groups $(n=564)$. Since a larger sample size results in more substantial statistical power to detect small differences, ${ }^{29}$ caution is required in interpreting the statistical significance in the 2J-OGS group. In this study, this discrepancy between group sizes was inevitable since 2J-OGS was more extensively performed than $1 \mathrm{~J}-$ OGS.

Among the dental characteristics, only maxillary ALD demonstrated a significant difference between the $1 \mathrm{~J}$ OGS and 2J-OGS groups. Crowding was the most frequently observed characteristics in the 1J-OGS group (52.7\%, $p<0.001$, Table 6), while spacing was the most frequent in the $2 \mathrm{~J}-$ OGS group $(40.4 \%, p<0.001$, Table 6). Furthermore, binary logistic regression analysis revealed that crowding and spacing in the maxillary arch significantly influenced the decision of the orthognathic surgery modality. The probability of 2J-OGS decreased when the patient had crowding in the maxillary arch 
(OR, 0.672; $p<0.05$; Table 8) and increased when the patient had spacing in the maxillary arch (OR, 3.645; $p$ $<0.001$; Table 8). This implies that 1J-OGS was chosen in patients with crowding in the maxillary arch since the proclined incisor and dental crowding could be concurrently resolved through tooth extraction while avoiding the invasive maxillary surgery. ${ }^{25,26}$ In contrast, 2 J-OGS was chosen in patients with spacing in the maxillary arch, for whom tooth extractions are generally contraindicated. ${ }^{25,26}$ Therefore, the maxillary surgery involving posterior impaction might be performed to normalize the flat $\mathrm{OP}$ and the proclined maxillary incisors. ${ }^{27}$

The normal overbite (1J-OGS and 2J-OGS; 53.2 and 52.0\%; Table 6) and hyper-divergent skeletal pattern (1J-OGS and 2J-OGS; 50.0 and 54.4\%; Table 7) were the most frequently observed characteristics in both groups, while the deep bite (1J-OGS and 2J-OGS; 5.9 and 7.4\%; Table 6) and hypo-divergent pattern (1JOGS and 2J-OGS; 9.1 and 9.9\%; Table 7) were least frequently observed. These mean that skeletal Class 111 with long face is the most prevalent, and extrusive dental compensation of the anterior teeth commonly occurred in these patients.

In both groups, more than $80 \%$ of the patients had CPD (1J-OGS and 2J-OGS; 80.1 and 82.8\%; Table 7) and approximately $50 \%$ of the patients had OP cant (1J-OGS and 2J-OGS; 49.5 and 52.3\%; Table 7), which could mean that approximately $30 \%$ of CPD manifests without OP cant. Therefore, in the patients with CPD and without OP cant, 1J-OGS with a rotational or bilateral differential mandibular setback might be indicated to correct the transverse discrepancies. ${ }^{30}$

Although some meaningful results were observed in this study, careful clinical implementation is needed due to the following limitations: (1) The geographic distribution of the hospitals was not fully equalized because some regional hub dental hospitals in the southeastern region in Korea were not included; (2) The sample sizes in each center were not the same. Since the subjects of the capital region comprised more than three-quarters of the total subjects, the larger sample size of the capital region could have affected the results. (3) A quantitative evaluation could not be performed because all the variables were categorical ones except operation age. This was inevitable because various analytical methods and cephalometric X-ray settings were used in the 10 centers. (4) All the subjects in this study were collected from the Department of Orthodontics in the university hospitals alone; none were included from the Department of Oromaxillofacial Surgery in the university hospitals nor private practice. Therefore, in future studies, it would be necessary to perform sophisticated statistical analyses guaranteeing regional and institutional equality, and include systematic data involving the orthodontic and surgical aspects.

\section{CONCLUSION}

- 2J-OGS was performed for more than three-quarters of the study population, despite regional differences.

- In both the 1J-OGS and 2J-OGS groups, males outnumbered females, and their mean operation age was older than females.

- The most frequent ALDs were crowding in the $1 \mathrm{~J}$ OGS group and spacing in the 2J-OGS group, while skeletal characteristics were not different between the $1 \mathrm{~J}-0 \mathrm{GS}$ and 2J-OGS groups.

- Spacing in the maxillary arch increased the probability of 2J-OGS, while crowding in the maxillary arch and normo-divergent pattern decreased the probability of 2J-OGS.

\section{CONFLICTS OF INTEREST}

No potential conflict of interest relevant to this article was reported.

\section{ACKNOWLEDGEMENTS}

This research was supported by a grant (BCRI20037) of Chonnam National University Hospital Biomedical Research Institute and a grant from the Korea Health Technology RetD Project through the Korea Health Industry Development Institute, funded by the Ministry of Health \& Welfare, Republic of Korea (HI18C1638).

\section{REFERENCES}

1. Zamboni R, de Moura FRR, Brew MC, Rivaldo EG, Braz MA, Grossmann E, et al. Impacts of orthognathic surgery on patient satisfaction, overall quality of life, and oral health-related quality of life: a systematic literature review. Int J Dent 2019; 2019:2864216.

2. Athanasiou AE, Melsen B, Eriksen J. Concerns, motivation, and experience of orthognathic surgery patients: a retrospective study of 152 patients. Int J Adult Orthodon Orthognath Surg 1989;4:47-55.

3. Proffit WR, Jackson TH, Turvey TA. Changes in the pattern of patients receiving surgical-orthodontic treatment. Am J Orthod Dentofacial Orthop 2013; 143:793-8.

4. Proffit WR, Phillips C, Dann C 4th. Who seeks surgical-orthodontic treatment? Int J Adult Orthodon Orthognath Surg 1990;5:153-60.

5. Boeck EM, Lunardi N, Pinto Ados S, Pizzol KE, Boeck Neto RJ. Occurrence of skeletal malocclusions in Brazilian patients with dentofacial deformities. 
Braz Dent J 2011;22:340-5.

6. Castro V, do Prado CJ, Neto Al, Zanetta-Barbosa D. Assessment of the epidemiological profile of patients with dentofacial deformities who underwent orthognathic surgery. J Craniofac Surg 2013;24:e2715.

7. Eslamipour F, Borzabadi-Farahani A, Le BT, Shahmoradi M. A retrospective analysis of dentofacial deformities and orthognathic surgeries. Ann Maxillofac Surg 2017;7:73-7.

8. Olkun HK, Borzabadi-Farahani A, Uçkan S. Orthognathic surgery treatment need in a Turkish adult population: a retrospective study. Int J Environ Res Public Health 2019;16:1881.

9. Baik HS, Kim KH, Park Y. The distributions and trends in malocclusion patients- a 10 year study of 2155 patients from YDSH. Korean J Orthod 1995; 25:87-100.

10. Hwang MS, Yoon YJ, Kim KW. An epidemiologic study on the orthodontic patients who visited Department of Orthodontics, Chosun University Dental Hospital last 10 years (1990-1999). Korean J Orthod 2001;31:283-300.

11. Im DH, Kim TW, Nahm DS, Chang Yl. Current trends in orthodontic patients in Seoul National University Dental Hospital. Korean J Orthod 2003;33:63-72.

12. Lee $\mathrm{CH}$, Park HH, Seo BM, Lee SJ. Modern trends in Class 111 orthognathic treatment: a time series analysis. Angle Orthod 2017;87:269-78.

13. Lee HY, Ahn Y, Park LY, Soh BS, Jo SK, Ko SO, et al. A clinicostastical study of inpatients of orthognathic surgery between 1993-2002. J Korean Assoc Maxillofac Plast Reconstr Surg 2004;26:477-83.

14. Lee SH, Park IS, Lee CH, Kwon TG, Yun M, Deng F. Clinicostatistical study on orthognathic surgery in our department. J Korean Assoc Oral Maxillofac Surg 2005;31:255-9.

15. Piao Y, Kim SJ, Yu HS, Cha JY, Baik HS. Five-year investigation of a large orthodontic patient population at a dental hospital in South Korea. Korean J Orthod 2016;46:137-45.

16. Jung $\mathrm{MH}$. Age, extraction rate and jaw surgery rate in Korean orthodontic clinics and small dental hospitals. Korean J Orthod 2012;42:80-6.

17. Lee SJ, Suhr CH. Recognition of malocclusion and orthodontic treatment need of 7-18 year-old Korean adolescent. Korean J Orthod 1994;24:367-94.

18. Sato FR, Mannarino FS, Asprino L, de Moraes M. Prevalence and treatment of dentofacial deformities on a multiethnic population: a retrospective study. Oral Maxillofac Surg 2014;18:173-9.

19. Sato S. Case report: developmental characterization of skeletal Class 111 malocclusion. Angle Orthod 1994;64:105-11; discussion 111-2.

20. Haraguchi S, Takada K, Yasuda Y. Facial asymmetry in subjects with skeletal Class 111 deformity. Angle Orthod 2002;72:28-35.

21. Arad 1, Jandu J, Bassett P, Fleming PS. Influence of single-jaw surgery vs bimaxillary surgery on the outcome and duration of combined orthodonticsurgical treatment. Angle Orthod 2011;81:983-7.

22. Bailey LJ, Duong HL, Proffit WR. Surgical Class 111 treatment: long-term stability and patient perceptions of treatment outcome. Int J Adult Orthodon Orthognath Surg 1998;13:35-44.

23. Bailey LT, Proffit WR, White RP Jr. Trends in surgical treatment of Class 111 skeletal relationships. Int J Adult Orthodon Orthognath Surg 1995;10:108-18.

24. Wolford LM. The sagittal split ramus osteotomy as the preferred treatment for mandibular prognathism. J Oral Maxillofac Surg 2000;58:310-2.

25. Kim DK, Baek SH. Change in maxillary incisor inclination during surgical-orthodontic treatment of skeletal Class 111 malocclusion: comparison of extraction and nonextraction of the maxillary first premolars. Am J Orthod Dentofacial Orthop 2013;143:324-35.

26. $\mathrm{Xu} \mathrm{B}$, Qin K. [The effect of extraction and non-extraction decompensation to bimaxillary orthognathic surgery in skeletal class 111 malocclusion]. Hua $\mathrm{Xi}$ Kou Qiang Yi Xue Za Zhi 2012;30:143-7. Chinese.

27. Bang SM, Kwon YD, Kim SJ, Lee BS, Choi BJ, Ohe JY, et al. Postoperative stability of 2-jaw surgery with clockwise rotation of the occlusal plane. J Craniofac Surg 2012;23:486-90.

28. Lee UL, Nam JH, Choi WC, Kim HW, Kim HJ, Choi YJ. Comparison of lip line cant change after 1-jaw and 2-jaw surgery. J Craniofac Surg 2019;30:18204.

29. Wasserstein RL, Lazar NA. The ASA statement on p-values: context, process, and purpose. Am Stat 2016;70:129-33.

30. Kim MS, Lim SH, Jeong SR, Park JH. Maxillary molar intrusion and transverse decompensation to enable mandibular single-jaw surgery with rotational setback and transverse shift for a patient with mandibular prognathism and asymmetry. Am J Orthod Dentofacial Orthop 2020;157:818-31. 